\title{
Experimental teaching mode in the application of mental health education
}

\author{
Li Xiaoyan ${ }^{1, a}$, Li Dayan ${ }^{2, b}$ \\ 1ldeological and Political Theories Teaching Research Departments, \\ Xi'an Technological University,Xi'an,710032,China \\ 2ShenMu county mining area middle school,Shaanxi, 719315,China \\ aemail: 397366628@qq.com, bemail:313678048@qq.com
}

Keywords: Mental Health; Effects of Teaching Experience; Teaching Effectiveness

\begin{abstract}
With the continuous improvement of quality of life, mental health education has been more and more attention. How to improve the classroom effectiveness, enhance their mental qualities are the main institutions of higher learning efforts to solve the problem.
\end{abstract}

\section{Introduction}

Rapid economic development in China today, the students outlook on life, values, and morality has undergone tremendous changes, especially after 80,90 students, nearly all of them only one child, the biggest feature is highly independent, to the traditional didactic teaching model based can not meet the requirements of the contemporary talents like training, so in college, "Education reform" has become a hot topic. As educators, mental health and how to more effectively improve the psychological quality of students, teaching in their daily work we have done a superficial attempt.

\section{The Characteristics of Experimental teaching model}

Experience teaching absorbed Learning Theory and Education on the subject of scientific research results to the current quality of education, innovation and education requirements, as with the times [1]. "Experience" the most obvious feature of teaching in the classroom teaching is to treat each and every student in good faith, understanding the feelings of students, concerned about the emotional needs of students, focusing on emotional experience of students, teachers in the teaching process is not in the decision, control, guidance status of students, but in a position of equality with the students is listening and help students who are the organizers of classroom teaching. Its essence is to provide students with Experimental learning,

Sentiment in the experience of thinking, in the experience a success. "Experimental" teaching students to respect the unique experience as the prerequisite to the development of students for the purpose, focus on student initiative, initiative and independence of the play [2].

\section{Experimental teaching model application in the classroom}

In the opening of the "Students in Interpersonal Communications" class, we use psychological counseling in group counseling methods, the creation of a variety of contexts, so students in a variety of "experience" in the access to knowledge, understanding. In the teaching process, we are granted according to the specific characteristics of the course and the teaching content, design a variety of teaching methods.

\section{[1]Selecting the question in classification}

To solve the problems of the students really, and the students are interested in class, the lesson college students' interpersonal communication is the most important. In order to keep the classroom effect, help students to improve their interpersonal skills in need, we are taking the course in the 
college students' interpersonal communication of student to carry on the interview, carefully selected, make really shy, nervous, inferiority, lack of interpersonal skills of students in the classroom learning. Secondly, we further understand the hearts of students, the students question classification of personnel groups, separately carries on the group guidance activities, avoid all sorts of problems, causes the student in the class have something irrelevant, hang high feelings. Through contact with the students of class, make students realize the school will give yourself what aspects help, had important on thought understanding, thus raising the enthusiasm, initiative in class.

\section{[2]Building the platform to strengthen the communication}

Teachers in the teaching process is not in a position of decision, control and guide the students, but in equal status with students, is a student of the listener and helper, is the organizer of the teaching process. Teachers' main task is to make the classroom form a kind of harmonious atmosphere, to explore values, students get emotional experience is their mission. Because students are living individuals, and not accept the container of knowledge and what others control [3]. In the learning process, emotion plays a very important role, so we pay particular attention to the students in the classroom emotional need, understand the students feelings, let them to deepen mutual understanding in the experience. In the college students' interpersonal communication class, for many of the introverted, timid, lack of interpersonal skills of the students, we specially arrange a lot of experience activities to deepen our communication and get to know each other between classmates. "Untie thousands knot" activities, has just started several male students to flushed nervously, rarely speak to students at ordinary times, let alone pull the hand of the opposite sex. Crustily skin of head hold a girl's hand, palms have been sweating after a period of communication, they looked at the people's faces smiling, friendly, their inner tension disappeared slowly. A few class down , they began laughing.

\section{[3]Teaching through lively activities and mind games}

Creating participatory in class that getting more game activities, make the classmates everyone involved. In the process of simple game activities, let students deep understanding of life philosophy, to understand the psychology of theoretical knowledge. In the college students' interpersonal interaction in class, we through "with a cane for the blind", "I am your eyes" game activities, such as, making the students experience the blind people live hard, inspire their love to care for the blind, help the disabled. Play a crutch students talk about them in the process of travel with the blind, in the case of unable to speak, in order to make the blind walk smoothly, they use staircases, railings, walls and other external conditions, transform all kinds of body language to guide the blind. Throughout the activities, number of "crutches" students tired arm grieved, and they deeply realized the importance of cane for the blind, learned how to better service for others, difficult to herself, convenient to others, when others need most to a warm hand! Activities after the "walking stick" in blind sound sincere thank classmates feel after he got satisfy and happy to help others, also can realize the interpersonal smooth evelopment importance link is to let each other "has the value", because no one is willing to stay with old those who said they can't. Students scrambling to speak, communicate her feelings and thoughts, from many angles change their thinking, some classmates thus changed the opinion of disabled people and life, stretched out a helping hand to the weaker in life mostly.

\section{[4]Creating situation,pay attention to experience of students}

This teaching methods is making multidirectional information communication between teachers and students. In the teaching process through the novel and unique multimedia courseware can attract the attention of students, also can bring students to the teaching need as soon as possible scenarios and atmosphere, stimulate students' interest and thirst for knowledge. In college students' interpersonal communication class, by showing PPT "sentient water", guide students to voice their opinions, speak freely, fully respect the students' emotional experience, put the question to deeper. Classmates regrets in scientific experiments concluded, also was deeply amazed by the crystallization of human language to no awareness of water produced by the great force, also deeply 
realized the role of beauty of language in interpersonal communication: affirmation and praise of the language is interpersonal lubricant, is man's best cosmetics. If a person is often all must accept, praise, and he is sure to increase self-confidence, glowing, and thus have a positive attitude towards life. By playing PPT "carrots, eggs, and coffee beans in the water to boil after 15 minutes of change", cause deep reflection of the students, the same situation, three items results after being "test" so different? Everyday many people turn a blind eye to cause students deep introspection of the result of the experiment. Preaching the whole teaching process, there is no simple, no theory of knowledge, you learned how to correctly understand and treat setbacks, and secretly cheer: "after the setbacks, must like beans, efforts to adapt to the environment, and ultimately change the environment".

\section{[5] Independent education through Interpretation of life}

In the daily work of Psychological guidance, we found that part of the students' psychological problems tend to be concentrated, universality and epresentativeness. In school psychological counseling staff, in order to improve the efficiency, solve more psychological problems of students in psychological counseling center in September 2005 founded the "heart about av club", the students use camera to record the youth, to strengthen the function of the "help and self-help". "Heart about av" "college life script" selection activities, which are held every year in the daily life of the students psychological confusion and conflict through reality simulation, of unity of knowledge and interest [4], make the teaching process into daily life, art is changed, also make the students improve the learning interest in the role play and communicate, increased the mutual affection. Classmates wrote, directed, from play of multi-stage psychological drama stage, the students often meet in daily life of interpersonal relationships, economic difficulties, academic problems, employment pressure directly deduce out, is the mirror of the students in real life, for they eliminate mental pressure, reduce the inferiority, improve the ability to adapt to the environment, increase self-confidence, to set up a positive, optimistic attitude toward life has greatly promote role. Students participating in the psychological drama filming under the condition of the shortage of funds, ensure the quality to complete the task, to cultivate the unity cooperation, help each other, support each other, overcome difficulties, thrift quality, effectively improve the psychological quality. Watch the psychodrama reflects the psychological problems of students through plays reflect their own weaknesses, thought-provoking, thought-provoking; Secondly look at screen familiar environment, familiar with classmates, students interested in psychodrama greatly strong, studio always all is people mountain people sea, click-through rate is also high on the Internet.

In the use of lens, through deductive side of men, education people around him, and on mental health education up to twice the result with half the effort.

\section{The "experience" the practical effect of teaching}

[1]It is benefit to Conducive to the students' interest in learning, stimulate students' creativity

The previous didactic-based teaching methods, ignoring the subjectivity of students, students in the classroom failed to arouse interest in the excitement, the lack of direct perception that all students experience the process, are passive recipients of knowledge, students generally feel tired, also difficult to stimulate the creativity of students out. Teaching experience is completely changed this situation, through a variety of teaching methods, students experienced the interactive mode of teaching, to really participate in the teaching, be able to experience secondary schools, secondary schools in the sentiment, on the basis inspire students multi-level, multi-angle of thinking, which burst out of the spark of innovation [4].

\section{[2]Help strengthen the "Three Views" of education, improve teaching effectiveness}

In the fact, the kind of moralistic is very poor to "Three Views" practical effect , often students will have resistance. Especially for today's students who are in economic and social, even more so. Through classroom practice, we believe that teaching experience in this area has a unique advantage. 
Teaching through the creation of a large number of activities for students to experience some sort of experience, access to real feelings, to form an inner resonance, self-realization of self-education and self-improvement. Thus, education students will really into the inner spiritual world and life in the hearts of the students left a meaningful mark, only to "wind sneaked into the night,moisten things silently "effect, thereby enhancing the effectiveness of teaching.

[3]Help create a harmonious atmosphere, and the establishment of good teacher-student relationship

Traditional didactic teaching, the students ignored the initiative, the students simply as "the audience, the audience," is a "teacher" for educators, "students" for being blunt teacher-student relationship educators [5]. The experience of teaching, the teacher's "guide" and students "experience" were placed in a situation and atmosphere, often showing the participation of teachers and students, interaction, sharing and communication, understanding, comprehension, teachers and students experience with new knowledge, together with emotional insight, each from each other, all this makes teaching the two sides closer together and produce a psychological feeling of resonance,

Let students feel the teacher amiable, respectable, credible personal charm, in order to establish democracy and equality in teacher-student buddy-type relationship, so teachers and students to become a harmonious partnership, friendship.

Through years of teaching practice, we believe that Experimental teaching the practical application of greater value, should be a good way of teaching in various disciplines to be promoted and strengthened.

\section{References}

[1] Shangfeng $\mathrm{Hu}$, Tian Tao, “Experimental teaching mode first exploration”, Education exploration , [J] ,Nov,2003,49-51

[2] Ping Han, mental health education calls "Experimental education" HeiLongJiang Education", [J] 2003, (10), 34-35.

[3] Shengyuan Yao, Yue Yu, "explained Five Steps to Teaching", the classroom teaching model , Education Exploration, [J] 2002, (6),12-13.

[4] Guanzhi Dong , teaching and practice of innovation, Tourism Tribune, [J]2003, (4),42-45.

[5] Changming He, "Experimental" teaching principles, strategies methods, http://www.jiaoan.net/lunwen/html. 